\title{
Reablement in need of theories of ageing: would theories of successful ageing do?
}

\author{
Jette Thuesen ${ }^{1 \star}$ (D), Marte Feiring ${ }^{2}$ (D), Daniel Doh $^{3}$ (D) and Rudi G. J. Westendorp ${ }^{4}$ (D) \\ ${ }^{1}$ REHPA, The Danish Knowledge Centre for Rehabilitation and Palliative Care, University of Southern \\ Denmark, Nyborg, Denmark, ${ }^{2}$ Faculty of Health Sciences, Department of Physiotherapy, Oslo \\ Metropolitan University, Oslo, Norway, ${ }^{3}$ School of Social Science, Western Sydney University, Penrith, \\ Australia and ${ }^{4}$ Department of Public Health and Center for Healthy Aging, University of Copenhagen, \\ Copenhagen, Denmark \\ *Corresponding author. Email: jette.thuesen@rsyd.dk
}

(Accepted 21 July 2021)

\begin{abstract}
The reablement approach is becoming a popular social and health-care model in many Western countries, providing support strategies for older people experiencing impairment. Reablement programmes have been criticised for a lack of theories, explicating the understanding of the problem that it is intended to address, i.e. ageing and impairment in old age. We need to discuss the inherent theories in intervention programmes to question taken-for-granted assumptions about not only what works, but also how these assumptions affect the sociocultural models of ageing. Theories on successful ageing have been suggested as underpinning reablement. This article aims to present and discuss theories of successful ageing compared to key principles, components and outcomes in reablement. A medical and epidemiological, a psychological and a sociocultural theoretical approach to successful ageing are included. Contemporary reablement programmes mirror medical and psychological theories of successful ageing, including models of ageing that are associated with continuity, optimisation, selection, individuality and goal orientation. Most reablement programmes do not address sociocultural perspectives on ageing. As older people experience impairment in a pertinent liminality within and between the sociocultural values of the third and fourth age, it is important for reablement programmes and practice to consider the theoretical assumptions and underpinning theories of ageing and how to help older people balance between optimising capacity and accepting losses in their everyday life.
\end{abstract}

Keywords: reablement; successful ageing; critical gerontology; liminality

\section{Introduction and background}

The reablement approach is becoming an increasingly popular social and healthcare model in many high-income Western countries; its goal is to provide short-

(C) The Author(s), 2021. Published by Cambridge University Press. This is an Open Access article, distributed under the terms of the Creative Commons Attribution licence (http://creativecommons.org/licenses/by/4.0/), which permits unrestricted re-use, distribution, and reproduction in any medium, provided the original work is properly cited. 
term support strategies for older people with impairments. As a concept, reablement was first defined in the late 1940s, but over the past three decades, the practice has been introduced into long-term care for older people (Clotworthy et al., 2021). Reablement has been described as an innovative approach to improving health-care services for older adults who are in need of care and support or at risk for functional decline (Cochrane et al., 2016). With ageing populations growing, the European Union has recommended reablement as a 'policy tool offering a new capacity with which the welfare state may manage and address more dynamically the societal risks associated with the ageing of populations' (Rostgaard, 2015: 161). Reablement represents a shift from a reactive to a more preventive and proactive model of home care provision, and it is based on early intervention and active engagement in reablement (Legg et al., 2016). Thus, reablement represents a re-orientation of home care 'away from treating disease and creating a dependency to maximizing independence' (Cochrane et al., 2016: 7). A quantitative and qualitative review of the incidence and content of the concept across time and space indicates that reablement has had a large impact; in particular, governments throughout the Western world have rapidly implemented reablement in recent years. Reablement has been criticised for a substantial lack of consensus regarding the concept as well as the structure, processes and potential outcomes of reablement (Clotworthy et al., 2021). To address this, a Delphi study was conducted in 20182019 with the aim of reaching agreement on the characteristics, components, aims and target groups of reablement, leading towards an internationally accepted definition of reablement (Metzelthin et al., 2020).

Moreover, reablement has been criticised for a lack of explicating the theoretical assumptions regarding the services in focus. In a review, Legg et al. found that

There is no well-developed understanding of the problem that it is intended to address, and the intervention lacks any explicit conceptual or theoretical framework. There is no clearly defined theory of change or mechanisms by which a reablement intervention programme might achieve its intended outcomes. (Legg et al., 2016: 746)

Intervention programmes should always state the theoretical assumptions behind how and why the programme will work, including theories of change (Kellogg Foundation, 2004). Theoretical assumptions are inherent in all interventions and inform professional actions, whether they are explicated or not (Hammell, 2006: 3). To question otherwise taken-for-granted issues, the theoretical basis for interventions must be explicit (McPherson et al., 2015). The above-mentioned Delphi study (Metzelthin et al., 2020) and key reviews from within the last 10 years either confirm the lack of theories (Doh et al., 2020) or do not mention the theoretical assumptions underpinning the programmes at stake (Cochrane et al., 2016; Faria et al., 2016; Tessier et al., 2016; Sims-Gould et al., 2017). In their review on reablement programmes, Moe and Brinchmann (2016: 8) found an implicit theory of optimising capacity, a theory which 'represents a relatively optimistic view of elderly care and might provoke service users, caregivers, and health personnel who have different and difficult experiences of elderly care'. They conclude that 'this review revealed a lack of theories exploring the experiences of reablement service users 
and their caregivers' (Moe and Brinchmann, 2016: 32). Other researchers have suggested that reablement represents a new paradigm, encapsulating the ideals of active ageing and continuing development throughout life (Ryburn et al., 2009; Rostgaard, 2015; Clotworthy, 2017; Bødker, 2019; Clotworthy et al., 2021). The logic(s) of reablement and the specific rationality and assumptions about impairment in old age enacted have been identified as drawing upon the theories of 'successful ageing' and an expectation that older people have the potential to regain lost capabilities that can (and should) be mobilised (Clotworthy, 2017; Bødker, 2019). The theories of successful ageing, however, have not been further discussed in relation to reablement.

The aim of this paper is to discuss how key principles, components and outcomes in reablement correspond with the paradigm of successful ageing and how a critical perspective on successful ageing may be addressed in reablement. Though there is no universally accepted definition for successful ageing (Clotworthy, 2017), Bülow and Söderqvist (2014) and Kusumastuti et al. (2016) have pointed out two distinct branches of theorising about successful ageing which have origin in two scholarly traditions: a medical and epidemiological perspective introduced by Rowe and Kahn in the 1980s (Rowe and Kahn, 1987) and a psychological perspective introduced by Baltes and Baltes at almost the same time (Baltes and Baltes, 1990). We will discuss how insights from these classic theories on successful ageing may or may not reflect key principles, components and expected outcomes in reablement programmes, and how they provide understandings of the problem that reablement is intended to address, i.e. ageing and impairment in old age. Moreover, we will include an additional critical perspective on successful ageing, developed in social gerontology (Grenier, 2012).

\section{Methods and materials}

This article narratively presents and discusses theoretical perspectives on 'successful ageing' in relation to key components, principles and outcomes in reablement. A medical and epidemiological perspective is represented by two papers by Rowe and Kahn on their theory of successful ageing (Rowe and Kahn, 1987, 1997), and a psychological perspective is represented by two papers on Baltes and Baltes' theory of successful ageing, selective optimisation and compensation (Baltes and Baltes, 1990; Baltes and Carstensen, 1996). We have added a sociocultural perspective represented by Grenier's theory about transition, continuity and change in old age, which links sociocultural structure and the lived experience of older people (Grenier, 2012). In her work, Grenier specifically reflects on the aforementioned theories of successful ageing and discusses the sociocultural perspective of transition and change in old age as a complementary, necessary objective to successful ageing.

The influence of Rowe and Kahn and Baltes and Baltes is well documented as being the most benchmarking in contemporary thinking of successful ageing (Bülow and Söderqvist, 2014; Kusumastuti et al., 2016). The included papers are selected with reference to these sources. Grenier has significantly influenced the field of social and critical gerontology through her numerous articles and books (Semantic Scholar, nd), and as moderator of the international network for 'critical 
gerontology' since 2008 (Grenier, 2020). It is for these reasons that in our analysis, we juxtaposed these three theoretical perspectives with the key principles and current practices in reablement. Although there is extensive secondary literature on the theories of successful ageing, we consider the selected original sources provide sufficient information to show our case.

\section{Successful ageing, a medical and epidemiological perspective}

Epidemiologist John W. Rowe, MD and psychologist Robert L. Kahn first launched their theory of 'successful ageing' in 1987 (Rowe and Kahn, 1987). Using predetermined, objective criteria related to physical and cognitive functioning, Rowe and Kahn's errand was to classify people as functioning at a high, medium or low level. Their studies were conducted within a cohort population of community-dwelling older people aged between 70 and 79. Rowe and Kahn considered high levels of cognitive and physical functioning to be necessary for independent living and quality of life, and a high level of functioning was therefore a proxy for successful ageing. Since then, many other observational cohort studies have been conducted using a similar or an adapted external standard to classify people as (un)successful (Kusumastuti et al., 2016). Although the concept was originally defined as a combination of high physical and cognitive functioning, follow-up studies diagnosed people as ageing 'successfully' based on certain physical or cognitive cut-offs (Rowe and Kahn, 1987).

Rowe and Kahn's concept of 'successful ageing' assumes that aged-related decline can be explained by extrinsic factors, i.e. factors that are external to the individual beyond ageing itself, and that these factors can be modified. Moreover, Rowe and Kahn argued that an interaction between physiological ageing and psychosocial ageing provides a broader perspective with which to understand the ageing process. The authors made a distinction between 'usual' ageing and 'successful' ageing. Older people who, regardless of age, have not experienced a decline in any given area of disease should be considered 'successful', bearing in mind the heterogeneous nature of any given population. The belief that, regardless of age, people can live functional lives with or without disease underscored the need to examine those factors that explain why, in a given cohort of older people, some may show signs of decline while others do not. Rowe and Kahn explained that, from a medical perspective, extrinsic factors such as diet and exercise are potential predictors of various disease conditions in old age. Moreover, these factors may be influenced by psychosocial factors that are also shaped by the conduct of family members, friends and health professionals. Thus, Rowe and Kahn (1987) suggested that there is evidence for the malleability of the ageing process.

In 1997, Rowe and Kahn further developed their theory, explaining that successful ageing is comprised of three main components (i.e. predictors): low probability of disease and disease-related disability; high cognitive and physical functional capacity; and active engagement with life (Rowe and Kahn, 1997). Having a low probability of disease and disability includes both the absence of a given disease and the severity of risk factors associated with the disease. High functional capacity refers to the individual's capacity for activity, while active engagement relates to the individual's ability and potential for social interaction, e.g. contact and transaction. Rowe 
and Kahn (1997) suggested that, because it is possible to modify the extrinsic factors associated with successful ageing, then it should also be possible to modify the extrinsic risk factors associated with disease and disability (e.g. lifestyle, improving cognitive and physical function); doing so could potentially result in successful ageing.

Rowe and Kahn's work has been influential in many ways. By demonstrating the plasticity of old age, they sent a message that 'positive change is possible' (Rowe and Kahn, 1997: 437). They also opened a new space for optimisation and enhancement in old age, as captured in this quotation:

The previously held view that increased risk of diseases and disability with advancing age results from inevitable, intrinsic aging processes, for the most part genetically determined, is inconsistent with a rapidly developing body of information that many usual ageing characteristics are due to lifestyle and other factors that may be age-related (i.e. they increase with age) but are not age-dependent (not caused by ageing itself). (Rowe and Kahn, 1997: 434)

\section{Reablement and medical perspectives on successful ageing}

Rowe and Kahn's approach represents a model of successful ageing that is associated with ideas that focus on continuity, active engagement and the optimisation of functioning. These ideas are echoed in the goals and principles of reablement. Reablement aims to support older people in increasing or maintaining their functional ability, independence and self-reliance in order to resume activities of daily living (Cochrane et al., 2016; Legg et al., 2016). By helping older people regain or maintain certain physical and/or other abilities, reablement aims to support them in overcoming functional decline (Metzelthin et al., 2020). According to the logics of reablement, older people have the potential to regain lost capabilities that can (and should) be mobilised (Clotworthy, 2017; Bødker, 2019). That is, some key principles in reablement correspond with Rowe and Kahn's theories on successful ageing, suggesting that later life is merely a continuation of a person's overall life trajectory and their development throughout life. From this perspective, being actively engaged in activities of everyday life and optimising functional abilities seems to be both the means and an end in reablement.

The medical and epidemiological theory on successful ageing has been criticised for its normativity. By equating 'successful' with the absence of disease and disease-related disability and with high cognitive and physical functional capacity, the paradigm is producing as its opposite an un-successful ageing, which is the presence of disease and disability and low functional capacity (Holstein and Minkler, 2003). As put forth later in this paper, the focus on individually formulated goals in reablement may attempt to avoid such a normativity.

While Rowe and Kahn predominantly dealt with the medical and epidemiological perspectives, some contemporary colleagues developed ideas on how to age successfully from a psychological perspective.

\section{Successful ageing, a psychological perspective}

In the late 1980s, German psychologists Paul B. Baltes and Margret M. Baltes developed a so-called 'meta model' of successful ageing. Their model was developed in 
response to the inadequacy of existing objective and subjective criteria for successful ageing. Baltes and Baltes believed that, when used separately, these criteria failed to address important aspects of quality of life. Rather, they stated that an encompassing definition of successful ageing required a value-based, systemic and ecological perspective. In a widely cited article from 1990 (Baltes and Baltes, 1990), they suggested an alternative model that integrated multiple objective and subjective criteria, and explicitly recognised individual and cultural variations.

Baltes and Baltes presented seven propositions about the nature of ageing from a psychological point of view: (a) a distinction between normal, optimal and pathological ageing; (b) inter-individual variability (heterogeneity); (c) plasticity and latent reserve capacity; (d) ageing loss in the range of reserve capacity or adaptivity; (e) the enriching and compensatory role of individual and social knowledge, including technology; (f) ageing-related changes towards an increasingly negative balance in gain-loss ratios; and (g) the phenomenon of a resilient self. Based on the framework of propositions about the nature of ageing, they suggested 'selective optimization with compensation' (SOC) as a prototypical strategy for successful ageing (Baltes and Baltes, 1990).

The authors explained that SOC involves focusing individual attention on more pressing and specific goals (selection), then taking actions to achieve these goals (optimisation) and putting mechanisms in place to maintain function amidst loss and decline (compensation). According to their model, the adaptive task of the ageing individual is to select and concentrate on those domains that are of high priority and which involve a convergence of environmental demands and individual motivations, skills and biological capacity. In essence, the SOC model asserts that individuals make conscious efforts to improve their development by adapting to ways and behaviours that maximise gains and minimise losses throughout the lifecourse. This model gains increasing importance in older age due to the increased vulnerability, reduced reserve capacity and increasing individualisation of life trajectories.

The authors further developed and operationalised this model in subsequent years. For example, in an article from 1996, Margret Baltes (writing with psychologist Laura L. Carstensen) defined 'success' as goal attainment; 'successful ageing' was thereby the minimisation of losses and the maximisation of gains. Hence, goals and goal setting became an important component in theories about successful ageing. Selection always entails the readjustment of individual goals, particularly the selection of high-priority domains, tasks and goals for further enhancement. Compensation can become necessary in domains that are not selected, e.g. the delegation of activities to somebody else (Baltes and Carstensen, 1996).

According to Baltes and Carstensen, society plays a central role in providing environments that facilitate optimisation, and they suggested that older people often live in a world of under-demand rather than over-demand. Optimisation is thus dependent on the possibilities and opportunities that are available (Baltes and Carstensen, 1996).

Baltes and Carstensen advocated a process-oriented approach to successful ageing that considers the interplay of gains and losses that are part of later life. Rather than deny the inevitable losses that older people experience in advanced age, the SOC model implies that old age holds the potential to be a time when the 
knowledge and expertise gained over a lifetime becomes invested in the realisation of a distilled set of highly meaningful domains and goals. In this view, the processes of SOC enable people to master desired goals despite - or perhaps even because of losses and increasing vulnerabilities. Thus, even losses may lead to gains in some highly valued areas of life (Baltes and Carstensen, 1996).

\section{Reablement and the psychological perspective on successful ageing}

The psychological perspective on successful ageing addresses that ageing is not just about continuity but also about adapting to change. This resonates with ideals for reablement, formulated by the International Federation on Ageing (IFA). According to the IFA, reablement is

an active process of (re)gaining skills and confidence in maintaining or improving function, or adapting to the consequences of declining function. It also supports the individual to remain socially engaged within the community context in a safe, culturally sensitive and adaptive way. (Mishra and Barratt, 2016: 7)

That is, reablement is also meant to be about helping older adults adapt to the consequences of declining function. This is in contrast to the ideals set forth by Rowe and Kahn because they consider high levels of cognitive and physical functioning to be necessary for a high quality of life and thus a proxy for successful ageing. In their view, 'positive' change in old age is associated with enhancement and optimisation.

In accordance with reablement's focus on adapting to change, Baltes and colleagues describe ageing as a process of selection that is associated with optimisation and compensation, as well as the pursuit of individually formulated goals. This psychological perspective represents a more balanced approach than Rowe and Kahn's due to its emphasis on the significance of optimal functioning. A person selects valued activities and domains in everyday life according to their own personal goals and what they consider to be essential. These ideas are echoed in versions of reablement that focus on choice (Legg et al., 2016) and individuality (Mishra and Barratt, 2016). According to leading scholars, reablement should support the individual in pursuing selected goals that are important to them (Mishra and Barratt, 2016; Tuntland, 2017; Doh et al., 2020; Metzelthin et al., 2020). Scholars have discussed independence as a goal and have stressed the importance of taking into account the individual goals of older people to balance between striving for independency in some activities while being supported in others (Metzelthin et al., 2020). However, empirical studies have argued that not all individual goals are legitimate in reablement practice if they do not correspond with the institutionally formulated goals (Bødker, 2019). This may be further reinforced by a political and societal ambition to reduce the costs related to home care for elderly people (Clotworthy, 2017).

Although reablement may emphasise individual choices and goals, these choices and goals are never carried out in a neutral context. Optimisation and compensation are clearly dependent on the possibilities and opportunities that are available. Moreover, the capacity to choose and to formulate goals are not equally distributed. Therefore, we will discuss the relevance of a sociocultural perspective to the two scholarly traditions above. 


\section{Successful ageing and a sociocultural perspective}

Canadian sociologist Amanda Grenier has explored transitions in later life, particularly people's experience of ageing and impairment, including success as a lived experience. She adopts a critical gerontological approach, bringing a perspective from the humanities and social sciences to the traditional natural-scientific approach to ageing. According to Grenier, the experience of ageing and/or impairment in later life is framed by and negotiated in relation to structural aspects such as dominant discourses and modes of thinking. She explores both older people's individual narratives and sociocultural constructs of ageing, as well as the intersections between them (Grenier, 2012).

According to Grenier, older people experience ageing and impairment differently. Some may not consider the onset of impairment in old age to be a significant transition. Others have the potential to shape their transitional experiences through identity and lifestyle choices while impairment may mark a significant transition to others, e.g. entering a more permanent state of uncertainty characterised by emotional ambivalence. Older people often have a strong desire to achieve continuity in certain aspects of their lives, as continuity indicates the possibility for agency, choice and self-determination. However, regardless of their personal wishes, impairment may prevent this continuity; even adaptation to new circumstances may be difficult. Thus, experiencing impairment in later life creates tension between continuity and change as a more permanent issue (Grenier, 2012).

To understand the state of uncertainty in relation to impairment in later life, Grenier applies the concept of liminality. The term 'liminal' - which means threshold or 'in-between' - was initially used by anthropologists to refer to the medial stage of a rite of passage or transition. According to Grenier, the experience of impairment in old age may also be understood in terms of liminality; specifically, as the space within and between the third and the fourth ages. The third and the fourth ages are sociocultural constructs (Higgs and Gilleard, 2015) that represent significant modes of thinking and practice, particularly in terms of how they frame the experience of impairment in later life. For more than four decades, social gerontologists and others have categorised the third age as a time of freedom, activity, continuity, independence and choice; conversely, the fourth age is characterised by decline, impairment and a lack of agency (Laslett, 1991; Gilleard and Higgs, 2010). According to Grenier, there is an increasing polarisation between the third and the fourth ages; the former has a positive connotation while the latter represents a sociocultural devaluation and a negative assumption of bodily decline (Grenier, 2012).

Following Bhaaba (in Ashcroft et al., 2013), Grenier considers liminality to be the experience of impairment in later life; it is both within and between, and thus a space for cultural changes. Rather than considering liminality to be a temporary space in between, she suggests a post-colonial definition of liminality, which suggests viewing this space as one of negotiation; a 'space of symbolic interaction' (Grenier, 2012: 133). Being within and between a situation of impairment in later life simultaneously represents time as being between (and within) the third and fourth age; it thereby negotiates both identities. Understanding older people as being both 'within and between' in this way opens a space for rethinking the 
conditions, experiences, assumptions and subjective experiences of living (or of adjustment and coping).

When identity (and success) is negotiated in a space between the realities of impairment, sociocultural constructs and subjective interpretations, then the binary division and polarisation between the third and the fourth ages (including the devaluation of the fourth age) may negatively influence older people's interpretations. Activities that one can no longer manage are judged in this context; this may in turn affect personal interpretations of success in relation to later life. Moreover, it may work to solidify the state of liminality and tension between the valorised third age and the devalued fourth age (Grenier, 2012).

\section{Reablement and a sociocultural perspective on (successful) ageing}

Nordic studies have revealed that professionals may face significant challenges in engaging older people in reablement. The logics of reablement do not always seem to correspond with the perspectives and strategies of older people experiencing impairment (Dahl et al., 2015; Meldgaard Hansen, 2016; Moe and Brinchmann, 2016; Bødker, 2019; Clotworthy, 2017). Grenier's sociocultural perspective might help us to understand why. Although reablement may emphasise individual choices and goals, which are considered to be individually valued, these choices and goals are never carried out in a neutral context. According to Grenier (2012), the capacity of the individual to select and define one's own destiny is often questioned by society (or is seen as less important). The older individual's capacity to choose thereby intersects with resources, cumulative disadvantages and the sociocultural context of choice. This leads us to question the focus on goal setting in both the psychological paradigm of successful ageing as well as in reablement practice. Continuity and high functionality are socioculturally valued, but may be challenged by impairment and a lack of resources; this creates a risk that one may fail to adapt and will then consider oneself to be a failure (Holstein and Minkler, 2003). The individual and collective handling of impairment is always negotiated in a sociocultural context, which supports some understandings and strategies while it devalues others. According to Grenier (2012), the sociocultural context for handling impairment is a valuation of the third age and a devaluation of fourth-age identities and strategies. When successful ageing is associated with third-age qualities, such as continuity and high physical and cognitive function, it contributes to an increasing polarisation between the third and fourth ages. The question is thus whether reablement policies and practices inadvertently do the same. More to the point, the question is whether individually formulated goals for retirement are valued as equally as the goals to optimise physical functioning, both by care professionals and by society at large.

\section{Discussion}

Theories inform professional actions. There is, however, a lack of making explicit the theories on ageing in reablement programmes. We have discussed three theoretical perspectives on (successful) ageing in relation to reablement: Rowe and Kahn's medical and epidemiological perspectives on successful ageing; Baltes and 
Baltes' psychological perspective on successful ageing; and Grenier's critical gerontological and sociocultural approach to ageing. These perspectives represent three different fields of gerontological research. Each of them is characterised by different key principles about ageing which may underpin or question key principles in reablement. The medical perspective stresses successful ageing as continuity, engagement and optimisation, reflected in key principles in reablement. The psychological perspective emphasises selection, individuality and goal orientation; principles which are also key principles in reablement. The sociocultural perspective suggests (successful) ageing as negotiated in a sociocultural context. This perspective may question how reablement programmes which are informed by the 'successful ageing' paradigm may incorporate the critique that has been raised towards this paradigm. It may incite considering how reablement and the larger sociocultural context of reablement inform these negotiations as well as the impairment interpretations of older people. As Grenier suggests, approaches based on the 'successful ageing' paradigm have unintentionally crystallised the frailties of impairment into what could be considered an unsuccessful late life (Grenier et al., 2017). She states that there is an urgent need to question the cultural ideal of independence in Western societies and to reconsider the significance of the fourth age being primarily associated with impairment and losses (Grenier, 2012; Grenier et al., 2017). In their position paper, Metzelthin et al., (2020) suggest a relative approach to independence as a goal: what is meant by independence may vary among older persons. However, many of the current reablement programmes define physical functionality and independence as key goals (Cochrane et al., 2016; Faria et al., 2016; Tessier et al., 2016; Doh et al., 2020; Clotworthy et al., 2021). If reablement should meet the goals and values of older people themselves, is functional independency a reasonable goal for reablement? Other scholars have indicated that when defining successful ageing, older people themselves emphasise the importance of social functioning more than physical and psychocognitive functioning (Von Faber et al., 2001). This insight reinforces the notion that, in order to align with older people's goals and values, reablement policy and practice should consider a more equal focus on social functioning as well as physical and cognitive functioning. Impairment is not necessarily considered to be a problem amongst older people themselves (Von Faber et al., 2001). This is supported by the so-called disability paradox, i.e. people can experience high satisfaction with life despite disability and impairment (Mehlsen, 2005; Puvill et al., 2016). Moreover, older people experience impairment in a pertinent liminality, balancing capacity and losses in their everyday lives (Grenier, 2012; Nicholson et al., 2012). Consequently, goals of independence should be balanced with other values, including wellbeing and the meaning of retirement.

\section{Conclusion}

The demand for making ageing theories explicit in reablement is well documented. We need to identify and discuss the theories enacted in intervention programmes to question taken-for-granted assumptions about not only what works, but also why it works - or why it does not. Moreover, we need to discuss how reablement principles and practices add to the sociocultural models of ageing. Contemporary reablement programmes mirror medical and psychological theories of successful ageing, 
including models of ageing that are associated with continuity, optimisation, selection, individuality and goal orientation. Most reablement programmes do not address sociocultural perspectives on ageing. As older people experience impairment in a pertinent liminality within and between the sociocultural values of the third and fourth age, it is important for reablement programmes and practice to consider how reablement may bridge the third and fourth ages and help older people balance between optimising capacity and accepting losses in their everyday life.

We suggest that theories of ageing underpinning reablement programmes and practice embrace the complexities of ageing in a physical, psychological and sociocultural perspective, recognising ageing as contextually negotiated. This includes avoiding polarisation between successful ageing and dependency, third and fourth age, continuity and change.

Acknowledgements. We thank Amy Clothworthy for assistance with proofreading which greatly improved the manuscript. The authors are affiliated with the international research network ReAble (https://reable.auckland.ac.nz/), although other ReAble members may not agree with all the conclusions of this paper.

Author contributions.

JT wrote the first draft of the introduction; DD and RGJW wrote the first draft of the Rowe and Kahn and the Baltes and Baltes section; MF and JT wrote the first draft of the Grenier section and the Discussion. Drafts were discussed by all authors and JT completed the final manuscript.

Financial support. This work was supported by VELUX FONDEN (JT, grant number 11637) and NORDEA FONDEN (RGJW, grant number 02-2017-1749).

Conflict of interest. The authors declare no conflicts of interest.

\section{References}

Ashcroft B, Griffiths G and Tiffin G (2013) Post-colonial Studies: The Key Concepts. Abingdon, UK: Routledge.

Baltes PB and Baltes MM (1990) Psychological perspectives on successful aging: the model of selective optimization with compensation. In Baltes PB and Baltes MM (eds), Successful Aging: Perspectives from the Behavioral Sciences. Cambridge: Cambridge University Press, pp. 1-34.

Baltes MM and Carstensen LL (1996) The process of successful ageing. Ageing \& Society 16, 397-422.

Bødker MN (2019) Potentiality made workable - exploring logics of care in reablement for older people. Ageing \& Society 39, 2018-2041.

Bülow MH and Söderqvist T (2014) Successful ageing: a historical overview and critical analysis of a successful concept. Journal of Aging Studies 31, 139-149.

Clotworthy A (2017) Empowering the Elderly? A Qualitative Study of Municipal Home-health Visits and Everyday Rehabilitation (Doctoral dissertation). Faculty of Humanities, University of Copenhagen, Copenhagen.

Clotworthy A, Kusumastuti S and Westendorp RGJ (2021) Reablement through time and space: a literature review of how the concept of 'reablement' has been defined and operationalised. BMC Geriatrics 21, 61.

Cochrane A, Furlong M, McGilloway S, Molloy DW, Stevenson M and Donnelly M (2016) Time-limited home-care reablement services for maintaining and improving the functional independence of older adults. Cochrane Database of Systematic Reviews 2016, CD010825.

Dahl HM, Eskelinen L and Hansen EB (2015) Coexisting principles and logics of elder care: help to selfhelp and consumer-oriented service? International Journal of Social Welfare 24, 287-295.

Doh D, Smith R and Gevers P (2020) Reviewing the reablement approach to caring for older people. Ageing \& Society 40, 1371-1383.

Faria R, Kiss N, Aspinal F, Harden M and Weatherly H (2016) Economic evaluation of social care intervention: lessons drawn from a systematic review of the methods used to evaluate reablement. Journal of Health Economics and Outcome Research 2, 1-6. 
Gilleard C and Higgs P (2010) Aging without agency: theorizing the fourth age. Aging and Mental Health 14, 121-128.

Grenier A (2012) Transitions and the Lifecourse: Challenging the Constructions of 'Growing Old'. Bristol, UK: Policy Press.

Grenier A (2020) International Network for Critical Gerontology. Available at https://criticalgerontology. $\mathrm{com} /$.

Grenier A, Lloyd L and Phillipson C (2017) Precarity in late life: rethinking dementia as a 'frailed' old age. Sociology of Health and Illness 39, 318-330.

Hammell KW (2006) Perspectives on Disability and Rehabilitation. Contesting Assumptions, Challenging Practice. Churchill Livingstone.

Higgs P and Gilleard C (2015) Rethinking Old Age: Theorising the Fourth Age. London: Macmillan International Higher Education.

Holstein MB and Minkler M (2003) Self, society, and the 'new gerontology'. The Gerontologist 43, 787796.

Kellogg Foundation (2004) WK Kellogg Foundation Logic Model Development Guide. Available at https:// www.aacu.org/sites/default/files/LogicModel.pdf.

Kusumastuti S, Derks MGM, Tellier S, Nucci ED, Lund R, Mortensen EL and Westendorp RGJ (2016) Successful ageing: a study of the literature using citation network analysis. Maturitas 93, 4-12.

Laslett P (1991) A Fresh Map of Life: The Emergence of the Third Age. Cambridge, MA: Harvard University Press.

Legg L, Gladman J, Drummond A and Davidson A (2016) A systematic review of the evidence on home care reablement services. Clinical Rehabilitation 30, 741-749.

McPherson K, Gibson BE and Leplège A (2015) Rethinking Rehabilitation: Theory and Practice. Boca Raton, FL: CRC Press.

Mehlsen MY (2005) Den paradoksale livstilfredshed i alderdommen [The paradox of life satisfaction in old age]. Psyke \& Logos 26, 609-628.

Meldgaard Hansen A (2016) Rehabilitative bodywork: cleaning up the dirty work of homecare. Sociology of Health and Illness 38, 1092-1105.

Metzelthin SF, Rostgaard T, Parsons M and Burton E (2020) Development of an internationally accepted definition of reablement: a Delphi study. Ageing \& Society. Available online doi:10.1017/ S0144686X20000999.

Mishra V and Barratt J (2016) Reablement and Older People. Final Report from Copenhagen Summit. Available at http://www.ifa-copenhagen-summit.com/wp-content/uploads/2016/04/CopenhagenSummit-Final-Report.pdf.

Moe C and Brinchmann BS (2016) Optimising capacity - a service user and caregiver perspective on reablement. Grounded Theory Review 15, 25-40.

Nicholson C, Meyer J, Flatley M, Holman C and Lowton K (2012) Living on the margin: understanding the experience of living and dying with frailty in old age. Social Science and Medicine 75, 1426-1432.

Puvill T, Lindenberg J, de Craen AJM, Slaets JPJ and Westendorp RGJ (2016) Impact of physical and mental health on life satisfaction in old age: a population based observational study. BMC Geriatrics 16, 194.

Rostgaard T (2015) Failing ageing? Risk management in the active ageing society. In Torbenfeldt Bengtsson T, Frederiksen $\mathrm{M}$ and Larsen JE (eds). The Danish Welfare State-A Sociological Investigation. New York, NY: Palgrave Macmillan, pp. 153-168.

Rowe JW and Kahn RL (1987) Human aging: usual and successful. Science 237, 143-149.

Rowe JW and Kahn RL (1997) Successful aging. The Gerontologist 37, 433-440.

Ryburn B, Wells Y and Foreman P (2009) Enabling independence: restorative approaches to home care provision for frail older adults. Health \& Social Care in the Community 17, 225-234.

Semantic Scholar (nd) Amanda Grenier. Available at https://www.semanticscholar.org/author/AmandaGrenier/4307282.

Sims-Gould J, Tong CE, Wallis-Mayer L and Ashe MC (2017) Reablement, reactivation, rehabilitation and restorative interventions with older adults in receipt of home care: a systematic review. Journal of the American Medical Directors Association 18, 653-663.

Tessier A, Beaulieu M-D, Mcginn CA and Latulippe R (2016) Effectiveness of reablement: a systematic review. Healthcare Policy 11, 49-59. 
Tuntland H (2017) Reablement in Home-dwelling Older Adults (Doctoral dissertation). Bergen, Norway: University of Bergen.

Von Faber M, Bootsma-van der Wiel A, van Exel E, Gussekloo J, Lagaay AM, van Dongen E, Knook DL, van der Geest S and Westendorp RGJ (2001) Successful aging in the oldest old: who can be characterized as successfully aged? Archives of Internal Medicine 161, 2694-2700.

Cite this article: Thuesen J, Feiring M, Doh D, Westendorp RGJ (2021). Reablement in need of theories of ageing: would theories of successful ageing do? Ageing \& Society 1-13. https://doi.org/10.1017/ S0144686X21001203 